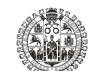 \\ VNiVERSIDAD \\ DSALAMANCA \\ TESIS DOCTORAL
}

\section{O Principezinho, de Antoine de Saint-Exupéry, como recurso didático numa educação intercultural}

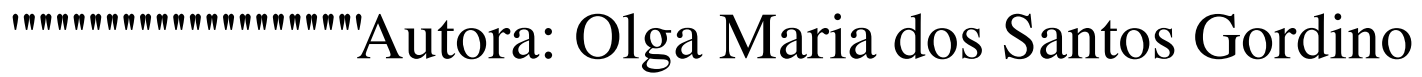

Director: Dr. José María Hernandez Díaz

Salamanca, 2015 


\section{Resumen}

Si uno pidiera a un artista que ejecutara un retrato de la sociedad actual, seguro que un mosaico de mil colores sería probablemente su obra más representativa. La analogía se apoya en la diversidad étnica, social, cultural y religiosa que progresivamente ha “colorido", y a nivel mundial, las sociedades de las últimas décadas. En el prólogo a la obra Leer la interculturalidad, Amelia Valcárcer $(2008: 22)^{1}$, nos enseña que "nuestro mundo afronta la multiculturalidad" que Isabel Tejerina (2008:41) define como la "existencia en un mismo tiempo y lugar de diferentes grupos culturales". Eso se debe al conjunto de cambios sociales, económicos, políticos y culturales. La sociedad se encuentra en una "vertiginosa transformación” (Penn \& Zalesne, 2008) de entre las cuales: la intensificación de los flujos migratorios, íntimamente conectada al proceso de globalización, en particular la creciente supresión, en el espacio europeo de Schengen ${ }^{2}$, de las barreras comerciales a la circulación de bienes y mercadorías, el desarrollo tecnológico, la revolución de los transportes, los medios de comunicación de masa y la interdependencia económica a la escala planetaria, entre otros. Toda esa afluencia y convergencia de flujos migratorios es responsable por la diversidad y por el fenómeno de la multiculturalidad. Este, aún que no sea reciente y desconociéndose si definitivo o provisorio ${ }^{3}$, constituye un tema actual y la preocupación asociada a él sigue ocupando un lugar preponderante en las agendas políticas internacionales por las repercusiones en varias áreas.

Si, por una parte, la diversidad es sinónimo de riqueza y de oportunidades, por otra, puede llevar a una tensión y al conflicto acaso no se verifica una integración eficaz de las personas y de sus culturas. Se constató que políticas de integración ineficaces potencian situaciones de conflicto porque exponen los grupos minoritarios, por si solo

\footnotetext{
${ }^{1}$ Valcácer, en el prólogo a la publicación dirigida bajo la coordinación de la profesora catedrática Isabel Tejerina pg. 22

${ }^{2}$ Espacio Schengen: nombre de la convención que instituyó que dejarían de existir fronteras entre los países que la hubieron firmado.

${ }^{3}$ En el prólogo a la obra supra citada coordenada por Isabel Tejerina (2008), A.Valcácer apunta para finales del Siglo XIX, momento en que "los flujos comerciales y políticos colocaron las diversas humanidades en contacto y la mundialización comenzó la volverse efectiva.” la autora, refiere aún que la multiculturalidad es un facto y probablemente el planeta será multicultural durante algún tiempo. Según la autora, no se puede asegurar por cuánto tiempo, ni tampoco hasta cuándo o aún si eso quedará para siempre.
} 
ya más vulnerables, a contextos sociales de riesgo de desempleo y de marginalización. Aunque el conflicto no sea necesariamente negativo, hay que saber tratarlo y posibilitar una resolución posible. La importancia de la cuestión planteó la reflexión sobre el problema en un lugar de destaque en la agenda política de la cimera de Lisboa de 2000, donde se apuntó el sistema escolar como potenciador para lograr la ya referida integración. Como respuesta a las preocupaciones en cómo tratar la diversidad se verifica, en variadas áreas, iniciativas con el objetivo de (ayudar a) integrar los que llegan. Integrar en cuanto se respectan y valorizan las orígenes de cada uno constituye el verdadero desafío. En las escuelas, el problema existe y con la agravante de tratarse de niños o adolescentes que, muchas veces, no encuentran otra salida que la del abandono escolar precoz provocado por la desmotivación de una desintegración en el microcosmos escuela. El derecho a la educación es una garantía para todos, defendida en el artículo XX de la Constitución Portuguesa. En Portugal, la Ley de la Inmigración n²3/2007, de 4 de Julio, por ejemplo, contempla medidas de apoyo en la educación que proponen integrar a los hijos de inmigrantes en las escuelas. El aprendizaje de la lengua del país que acoge, en cuanto condición sine qua non de una integración eficaz, que cuenta con programas de apoyo a la lengua portuguesa son un ejemplo de esas medidas elegidas por el sistema educativo. A nivel institucional, por ejemplo, se evidencia la creación, en 1991, del Secretariado Coordinador de los Programas de Educación Multicultural, a lo que sucedió el Secretariado Entreculturas, en 2001, que ofrece, desde 1993, una base de datos sobre la demografía multicultural en las escuelas de la red pública (Souta, 1999). Proponer y defender una educación para todos y con todos es la propuesta de todas las instituciones de educación . La operacionalización depende, en parte, de la autonomía de las escuelas y de su capacidad en responder a la cuestión. Por otra parte, hemos asistido a la experimentación de proyectos en el ámbito de la multiculturalidad y, más recientemente, a la creación de proyectos que abordan la situación utilizando la educación intercultural en cuanto propuesta para la integración. Efectivamente, la educación intercultural ha sido frecuentemente apuntada como solución para la integración de los alumnos oriundos de la inmigración (Abdallah-Pretceille, 1999) y aún esta no sea la sola posibilidad que ofrezca, constatamos que ella puede representar una indiscutible ayuda para el desafío que se coloca a las escuelas a nivel de integración de la diversidad cultural. Inclusiva, integradora y activa, la educación intercultural cada vez más es apuntada como estrategia a implementar y valorar ya 
que permite transmitir e introducir valores al mismo tiempo que fomenta el respecto por la diversidad. En cuanto proceso pedagógico, aproxima y posibilita el contacto entre las culturas y no se enfoca solamente en los hijos de inmigrantes sino también a todos los alumnos con el intuito de desarrollar el respecto, la tolerancia y la valoración de la diversidad. En cuanto proceso transversal, no hay que limitarlo sólo a una o dos asignaturas sino a todo el currículo concretizándolo en la preocupación diaria y continua de la práctica lectiva. Pero en cuanto posible solución, le hace falta más reflexión sobre el modo como su implementación puede ser conducida hasta el objetivo que con ella se logra conseguir.

El presente trabajo se presenta como un estudio exploratorio de las posibilidades de utilización de la literatura infantil como forma de promover la educación intercultural y responder a las necesidades de los alumnos provenientes de la inmigración. Con base en la reflexión conducida en el presente estudio, pretendemos contribuir para la construcción, a posteriori, de un proyecto que utilice y explote una obra de literatura infantil, El Principito, de Antoine de Saint-Exupéry en un abordaje intercultural. La propuesta nace de la necesidad de encontrar estrategias y contribuir, por medio de la reflexión sobre algunas prácticas, para las preocupaciones diarias de quien experimenta la situación de trabajar con alumnos oriundos de la inmigración y que muchas veces demuestra dificultades y frustraciones en integrarse e interactuar con los otros alumnos. Así la reflexión del presente estudio incidió particularmente sobre las estrategias que tienen que ser implementadas para trabajar positivamente con alumnos de diferentes orígenes culturales y sociales, con el intuito de proporcionar situaciones de aprendizaje activa participativa e igualitaria en convivencia con los otros alumnos con base en los presupuestos de educación intercultural. En la origen de esta reflexión se encuentra el recurso a la literatura infantil en un abordaje intercultural como estrategia. Reflecte así la preocupación personal en garantizar a todos las mismas oportunidades de aprendizaje y una plena participación en el proceso de enseñanza-aprendizaje, proponiendo un papel activo e integrador a todos los alumnos. La integración de alumnos provenientes de la inmigración constituye la preocupación primordial sobre la cual nos debruzamos en este estudio, partiendo del objetivo de encontrar estrategias de integración (en la escuela) de los alumnos inmigrantes con base en la educación intercultural por medio de la explotación de la literatura infantil. La idea subyacente y el principio orientador que delineó nuestro 
estudio ha sido lo de incentivar a la interacción entre los varios grupos, beneficiando de esa forma todos los alumnos y no solamente el grupo de alumnos inmigrantes, porque creemos que esa es la estrategia adecuada para la integración, en articulación con la teoría, que propone trabajar las relaciones inter-étnicas en cuanto que enriquece la experiencia de todos los otros alumnos que componen las clases multiculturales de gran parte de nuestras escuelas. En este trabajo, fue conducida una reflexión sobre la situación actual, de la cual emergen cuestiones como el modo cómo la literatura infantil puede proporcionar, a través de proyectos, una interacción entre alumnos por medio del recurso al intercultural. Con ese fin, en un primer momento se ha analizado una amuestra representativa de algunos proyectos europeos que proponen un abordaje a la educación intercultural por medio del recurso a la literatura infantil. Después de esa análisis, siguió una reflexión integradora donde la convergencia entre la teoría y la práctica nos permitió delinear algunos tópicos de explotación de obras de literatura infantil en proyectos de educación intercultural. A la luz de esa línea de convergencia, elegimos una obra de literatura infantil en particular, El Principito, de Antoine de Saint-Exupéry, explotando las potencialidades de utilización que ofrece para la construcción de un proyecto de abordaje intercultural.

Nuestro trabajo se distribuye en tres partes. En una primera parte, en cuanto capítulo introductorio, comenzamos por definir los conceptos transversales a nuestra reflexión, delineando el objeto de estudio y delimitando nuestro campo de actuación . En un primer momento presentamos conceptos empezando con el de inmigrante partiendo de una definición sociológica y jurídica, para alargar la reflexión al entendimiento que se hace del término en función del significado que el 'estado-nación' le da de acuerdo con la relación con sus inmigrantes. Seguidamente presentamos la situación actual de los hijos de inmigrantes en las escuelas, interesándonos su situación en cuanto alumnos en las escuelas. Para apoyar nuestra reflexión, recorremos a un estudio conducido por Machado y Matias de 2006, que distingue las fronteras tenues entre jóvenes inmigrantes e inmigrantes jóvenes, y donde los autores justifican el motivo por que rechazan las terminologías 'inmigrantes de primera' y 'segunda generación '. Completamos la definición anterior con una reflexión sobre la expresión que usamos y su justificación. Después de lo que, en un breve abordaje a las corrientes que antecedieron la educación intercultural, que Ouellet aproxima de la educación para la ciudadanía, explicamos como fue surgiendo la necesidad de 
gestionar la diversidad, evolucionando desde la mera aceptación y respecto por la diferencia hasta la necesidad de negociar sentidos e interactuar con la diversidad. La comunicación es condición sine qua non para hacer efectiva el cambio entre los grupos multiculturales. Distinguiremos los conceptos de educación multicultural y educación intercultural, insistiendo en un plan semántico en el prefijo 'inter' (en relación al 'multi') que marca la diferencia y que revela una actitud activa de integración en cuanto proceso intercultural por oposición a la convivencia pacífica del multicultural. La primera parte de este primer capítulo se concluye con una reflexión sobre las definiciones del concepto de literatura infantil según algunos autores, en cuanto enunciaremos nuestra propia concepción de literatura infantil, distinguiendo entre los conceptos por veces equivocadamente confundidos de literatura infanto-juvenil, literatura juvenil y afines. En un segundo momento, dentro de la primera parte, conducimos una reflexión sobre la importancia y la utilidad de la literatura infantil para servir los presupuestos de la educación intercultural. Consideramos que el recurso a los libros representa un instrumento valioso en cuanto contribuye para abordar la educación intercultural por varios motivos. En cuanto 'arte' la literatura infantil posee un sentido estético conectado al fenómeno comunicativo que invita a compartir y que, desde luego, proporciona un incentivo a la interacción. Por la etapa de desarrollo en que se encuentra el niño y por el abordaje a temas universales con los cuales el niño puede identificarse, la literatura infantil es facilitadora de un acercamiento entre el 'Yo' y el 'Otro', ora abriendo ventanas al desconocido, ora reflectando la identidad del otro. Además, propone crear puentes, entre Yo y el Otro, un camino de dos sentidos. Por lo que la reflexión sobre la utilidad de recorrer al libro infantil articulará en la práctica lo enunciado en teoría en el capítulo anterior. En seguida, presentamos un estado del arte en materia de inmigración e integración de alumnos inmigrantes en Portugal y en la escuela portuguesa. Presentamos hechos observados y datos concretos sobre la situación actual, con algunos resultados de estudios conducidos sobre el aprendizaje de esos alumnos y las medidas implementadas en la educación. Comenzaremos con un abordaje más general a la situación que se vive actualmente en la sociedad y sus consecuencias, para especificar algunos aspectos importantes, en un segundo momento, como la integración en las escuelas y las iniciativas que visan concretizar medidas presentadas a nivel institucional. Abordaremos cuestiones como la identificación de las dificultades de aprendizaje que los hijos de inmigrantes revelan, 
basándonos en los estudios PISA conducidos por la OCDE, y que indican principalmente, dificultades de origen lingüística, evidenciadas en el momento del aprendizaje de la lengua no materna, aún que esta no sea la única justificación . Concluiremos, a partir de esos estudios, que los alumnos oriundos de la inmigración frecuentemente presentan resultados que se acercan de los resultados de los alumnos nativos con la misma situación económico-social, por lo que deducimos que el problema tiene que ser (re)pensado a nivel de las políticas educativas y no puede reducirse solo a un dificultad lingüística. Además, esa opinión tiene más fuerza si observamos que algunos países presentan resultados muy nivelados entre los alumnos inmigrantes y los alumnos nativos, presentando paralelamente políticas de integración eficaces. Tras estas definiciones y reflexiones sobre la situación actual y los conceptos más teóricos, proponemos estudiar cómo puede la literatura infantil servir, en la práctica, los presupuestos de la educación intercultural, analizando un conjunto de proyectos europeos que utilizan los libros para el abordaje a la educación intercultural. Esta parte de nuestro estudio representa el resultado de la investigación que conducimos en el ámbito de la análisis a proyectos europeos de educación intercultural. Una vez que el presente trabajo constituye una contribución para la construcción de un proyecto que utilice la literatura infantil como recurso para la promoción de la educación intercultural en el sentido de ayudar a la integración de alumnos inmigrantes, era de importancia primordial que se reflectase y se analizase lo que se ha hecho en ese ámbito para intentar comprender cómo tiene que construirse un proyecto de ese tipo. Buscamos sistematizar lo que se ha hecho entendiendo cómo se ha hecho la articulación de la teoría con la práctica, por Europa. Insistimos, otra vez, sobre la idea de que la integración de alumnos oriundos de la inmigración representa una preocupación internacional ya que el mundo está en mutación y las sociedades occidentales tienen la obligación de revisar sus políticas de integración . Así, analizamos un corpus constituido por un conjunto de proyectos europeos que utilizan la literatura infantil para trabajar la educación intercultural. Parte de esa investigación ha sido conducida en el ámbito de una beca de investigación avanzada financiada por la Fundación para la Ciencia y Tecnología (FCT) y desarrollada en la Escuela Superior de Educación del Instituto Politécnico de Castelo Branco. El trabajo fue dirigido por las Profesoras Doctoras Margarida Morgado y Natividad Pires, respectivamente investigadora responsable e investigadora principal, intitulado 'Representações do Outro no Plano Nacional de Leitura Português (PNL): Estratégias 
para uma Educação Intercultural sobre as obras recomendadas para o $4^{\circ}$ ano do Ensino Básico'. El objetivo de la investigación, desarrollada en el ámbito más alargado de este proyecto y como parte de ello, ha sido lo de entender cómo la literatura infantil puede servir o no los presupuestos de la educación intercultural en proyectos conducidos por países europeos, que trabajan en parecería, financiados por programas Sócrates de acción Comenius, centrados en la educación, que utilizan la literatura infantil para promover la educación intercultural. Nuestra búsqueda incidió inicialmente en los proyectos disponibles en la Base de Datos ISOC del programa de acción Europeo SOCRATES, en el ámbito de la educación. Seleccionamos los que se incluían a la Acción Comenius, centrados en la Enseñanza Escolar, con el tema "Educación Intercultural - Lucha contra el racismo y la xenofobia". De todos los que encontramos, elegimos los que usaban la literatura infantil para promover la educación intercultural. Excluimos, por un lado, todos los proyectos que usaban literatura de tradición oral o "storytelling”(narrativas orales), los de escrita creativa como, por ejemplo, de recuento y también los que tenían enfoque en aspectos performativos de la literatura, como por ejemplo la dramatización de lecturas. Guardamos solamente para análisis, los proyectos que se servían de la literatura infantil en cuanto soporte escrito, bajo la forma de libro o de material en línea disponible en internet. Obedeciendo a los criterios enunciados, de un total de 326 proyectos, nuestra búsqueda resultó en 19 proyectos producidos entre 1995 y 2008 que analizamos individualmente de acuerdo con los siguientes criterios: la noción de cultura al que recorre; cómo usa la literatura infantil; las perspectivas de educación intercultural que promueve y las estrategias adoptadas, y finalmente, los puntos fuertes y débiles. Dado que muchos de los proyectos extraídos de la base ISOC, anteriores a 2008, todavía no usaban internet para la divulgación de sus productos o como soporte pedagógico, por lo que nuestra análisis para esos se basó solamente en la descripción disponible en la base. Los otros posteriores ya ofrecían un acceso más directo a la página internet o a las publicaciones, facilitando nuestra investigación y permitiéndola más rigurosas nuestras conclusiones. Organizamos los proyectos en dos grupos, para una mejor conveniencia de nuestra análisis. Juntamos por un lado los proyectos que inciden sobre la Educación intercultural a través de la lectura y por otro, los proyectos que construyen bibliotecas (inter)culturales. Verificamos que muchos de los proyectos explotan directamente la literatura infantil a través de imágenes o texto y otros la usan sólo como pretexto para la promoción de la 
educación intercultural. Constatamos también que algunos proyectos proponen sólo una comprensión de otras culturas, por la manera como la cultura puede influenciar el individuo, aun así quieren mejorar la interacción con el otro. Encontramos proyectos más cercanos de lo que defiende la educación intercultural y que tienen como objetivo el refuerzo de la relación entre culturas, otros pretenden divulgar conocimiento sobre otras culturas, subrayando una noción de "cultura europea", a veces, poco definida o buscando semejanzas y diferencias entre las distintas culturas. Destacamos de manera general la importancia del abordaje a temas universales que permite un acercamiento mayor ya que el niño se identifica mejor con lo que reconoce. Estos aspectos constituyen una etapa apenas del proceso de construcción de la relación con el otro que pasa por la comprensión, la análisis y la reflexión de los modos de relacionarse del individuo con su propia cultura y la de los otros y la mayoría de los proyectos tiene su enfoque en la gestión de la diversidad. Sin embargo, esa gestión de la diversidad carece de un trabajo de reflexión activo sobre la relación con el otro para promover la interacción. Lo que nos lleva la cuestionarnos si estos proyectos abrazan más los fundamentos de la educación multicultural que de la educación intercultural una vez que se preocupan más sobre el conocimiento del otro que sobre la interacción con él. Efectivamente, muchos de los proyectos tienen como objetivo conocer otra(s) cultura(s) sin promover la reflexión sobre la relación con el otro. Sin embargo, consideramos también que es la manera como cada profesor o educador utiliza estos proyectos que puede llevar a una interacción o no. Así, es importante que se creen condiciones para la construcción de la relación y una interacción en la diversidad. Concluimos con la idea principal defendida por Abdallah-Pretceille sobre la necesidad de comunicarse con el otro, de crear condiciones para acercarse y posteriormente permitir la integración . Pues en cuanto proceso activo de integración e interacción, la educación intercultural debe permitir la convivencia entre los individuos de distintas culturas, en el respecto mutuo y sin anulación de los trazos individuales. Consideramos, por eso, que de una manera global y de acuerdo con la utilización que se hace de cada proyecto, ellos pueden contribuir para la concretización de los objetivos de educación intercultural. Concluimos también que la utilización de la literatura debe conducir a una reflexión sobre la relación y no hace falta el uso exclusivo de libros multiculturales ya que es su explotación , por parte del profesor el educador, que podrá contribuir para esa reflexión y para la transformación de la sociedad para ser capaz de ayudar a los jóvenes a actuar y combatir todo tipo de 
discriminación . Veamos a continuación el ejemplo de una obra de literatura infantil en particular, El Principito, de Antoine de Saint-Exupéry para la construcción de un proyecto de educación intercultural. Nuestra elección tiene que ver por un lado por el gusto particular por esa obra, porque creemos que tiene potencial para servir de soporte la un proyecto que venga a abrazar el recurso a otras obras y porque consideramos que articula los presupuestos teóricos que fuimos desarrollando a lo largo del presente estudio. Así, con base en lo que se ha analizado en relación a otros proyectos y a la utilización que hacen de la literatura infantil al servicio de una educación para los valores, proponemos presentar una lectura critica de la obra para el abordaje a la interculturalidad. Así que, después de comparar lo que se propone en la teoría con lo que ya conocemos de El Principito, consideramos que se adecua al propuesto para una pedagogía del intercultural. Justificamos y explicamos, a continuación, por qué y cómo podemos usar ese libro como recurso didáctico en la educación intercultural. En primer lugar, es una obra universal y conocida en todo y por todo el mundo, existen traducciones en casi todas las lenguas habladas en el mundo, incluso dialectos como el mirandés y versiones en braille, para personas no visuales. La apropiación de una obra en otras lenguas acerca las distintas culturas, ya que las traducciones son puentes entre las culturas, de acuerdo con Cerisier (2006). El acceso al libro en cualquier lengua, permite también a los jóvenes de poder contactar con una lengua extranjera, aprendiendo vocabulario distinto de su propia lengua. Además, la lengua es la base de la comunicación . Por otra parte, el libro aborda temas universales como la amistad, el amor, la tristeza, la solitud, punto importante defendido por teóricos en nuestro estudio, ya que permiten a los lectores que se identifiquen mejor con los personajes y los temas porque la identificación es mejor a partir de los que se reconoce. Ese punto constituye uno de los objetivos de la educación intercultural, conseguido por la utilización de la literatura infantil y que permite acercar a los jóvenes de los personajes, interiorizando sentimientos, angustias y poniéndose en el lugar del otro.

La segunda parte de nuestro estudio incide sobre el potencial del libro de literatura infantil ya citado y la manera como puede usarse para servir la educación intercultural en las escuelas. Por los motivos ya expuestos, y tras las conclusiones a partir de la reflexión sobre los proyectos, se consideró que la universalidad de temas permite un acercamiento de los niños a los personajes, la reflexión sobre temas importantes como 
los preconceptos, la hegemonía de los grupos dominantes y la construcción de relaciones puede ayudar a transformar la sociedad, ya que es lo que se defiende en la educación intercultural, que sea activa y permita cambiar mentalidades y transformar la sociedad. Por lo que, analizamos el libro de acuerdo con los objetivos de la educación intercultural, conduciendo a una reflexión que podrá ayudar a los profesores a trabajar con el libro en clase. Después de presentar resumidamente el libro y su autor, cuya influencia en cuentos infantiles y en su propia biografía y vivencias de niñez son evidentes en toda la historia, proponemos una reflexión que resumiremos a continuación a la que se seguirá una lectura critica de la obra y en tercera parte, el diseño de un proyecto internet.

En su conjunto, la obra es rica en la reflexión que propone sobre la relación con el otro y las situaciones que potencian la comunicación . El modo como las relaciones ocurren y son explotadas se acercan de la educación intercultural respectando la diferencia y promoviendo la diversidad. Perotti (1994:53) defiende una pedagogía del intercultural, donde salienta el carácter dinámico de la misma "Mais do que educação, dever-se-ia falar de aprendizagem intercultural." y subraya que "[n]ão chega ainda que sea necessário- ter das outras culturas una ideia aproximada: é preciso que a ela se acrescente a vivência e a experimentação individual em situações interculturais" ${ }^{2}$. Esa convivencia que van experimentando los personajes en sus interacciones y el enriquecimientos de contacto con la diferencia se concretiza por las relaciones que se crean y se construyen durante la narrativa. Lo que pretendemos con nuestra análisis a la obra es llevar a una reflexión para que se mire El Principito, “[...] tendo em vista fomentar atitudes, modos de pensar e reações de leitura no âmbito intercultural" ${ }^{\prime 6}$ como defienden Morgado y Pires (2010:9). Pues también creemos como Salman Rushdie, citado por Morgado y Pires, que se "[...] pode pôr la literatura ao serviço dos interesses de la comunidade por possuir o poder de falar a muitas vozes e sobretudo, de todos os modos possíveis (mesmo de conflito)"7 (2010:13). Fue con base en esa afirmación que proponemos conducir nuestra

\footnotetext{
${ }^{4}$ Trad. nuestra: "Más que de una educación intercultural, deberíamos hablar de un aprendizaje intercultural”.

${ }^{5}$ Trad. nuestra: “ No llega - aunque sea necesario- tener una idea de las otras culturas: es necesario que a ella se le añade una vivencia y la experimentación individual en situaciones interculturales."

${ }^{6}$ Trad. nuestra: "teniendo en la idea de promover actitudes, modos de pensar y reacciones de lectura en el ámbito cultural."

${ }^{7}$ Trad. nuestra: " se puede poner la literatura al servicio de los intereses de la comunidad por poseer el poder de hablar a muchas voces y sobretodo, de todos los modos posibles (hasta mismo de conflicto)."
} 
investigación, intentando aprovechar el potencial de esta obra y concretizar, a través de prácticas de educación intercultural, el acto de poner la literatura al servicio de los intereses de la comunidad. El libro nos muestra cómo interactuar con la diversidad indicando modos de acercarse a pesar de las diferencias, sin preconceptos, o sea, propone mirar al otro con una mirada abierta y disponible, favorecer el diálogo y crear lazos. La obra funciona como un manual de instrucciones para la comprensión y el respecto del otro al mismo tiempo que permite un mejor conocimiento de si propio y del otro. El Principito, nos muestra como podemos convivir y aceptar las diferencias a través de la lectura crítica que proponemos, y que obedece la un conjunto de principios básicos enunciados por Belinda Louie (2006 apud Morgado y Pires, 2010:99):

1. verificar a autenticidade do que é representado no texto;

2. ajudar os leitores a compreender o mundo da perspetiva das personagens;

3. levar as crianças a procurar ver pelos olhos das personagens;

4. identificar valores que subjazem à resolução de conflitos entre personagens;

5. relacionar a experiência pessoal com o texto e com outros média;

6. usar variantes de uma mesma história para os alunos poderem compreender esquemas mentais básicos;

7. encorajar os alunos a falar, dialogar, escrever e reagir aos textos. ${ }^{8}$

La numeración de esos principios de lectura crítica es de nuestra responsabilidad y lo hicimos de manera a permitir hacer un paralelo con la pertinencia del libro que elegimos como recurso didáctico en la educación intercultural. Así, justificase, para 1. el hecho de que existen numerosas traducciones lo que demuestra la autenticidad de lo que está representado en el texto. En relación a los requisito 2. Y 3., conducir la reflexión de manera a conseguir ver con otros ojos la diferencia o interpretar una misma realidad de otro punto de vista, como veremos más adelante, comprueba esa preocupación . El requisito 4., podrá trabajarse analizándose la relación entre los personajes de la narrativa al mismo tiempo que se hace una reflexión sobre los conflictos que van surgiendo, entre el Principito y el Aviador, o con los habitantes de los planetas visitados, por ejemplo. El requisito 5. podrá ser cumplido, durante los

\footnotetext{
8 Trad.nuestra: 1. verificar la autenticidad de lo que está representado en el texto; 2. Ayudar a los lectores a entender el mundo desde la perspectiva de los personajes ; 3. llevar a los niños para intentar ver a través de los ojos de los personajes ; 4. identificar los valores que subyacen a la resolución de los conflictos entre los personajes ; 5 . Relacionar la experiencia personal con el texto y otros medios de comunicación; 6. Utilizar variantes de la misma historia para que los estudiantes puedan entender la perspectiva mental de base; 7. Alentar a los estudiantes a hablar, dialogar, escribir y reaccionar a los textos.
} 
distintos momentos de reflexión que nuestro estudio presenta en particular en su tercera parte, el proyecto internet donde los alumnos podrán relacionar las situaciones propuestas con su experiencia, y con lo que ya conocen. El requisito 6. Podrá lograr ejecutarse en las numerosas traducciones existentes y las que proponemos en la pagina internet del proyecto, las versiones en braille o en tebeos de una misma historia. Finalmente, el último requisito podrá ser cumplido con todas las actividades propuestas en el proyecto internet y con más gran incidencia en la plataforma interactiva, que explicaremos más adelante. El diseño del proyecto internet que presentamos en la tercera parte de nuestro estudio, concretiza los presupuestos teóricos, enunciados la primera parte, para una pedagogía del intercultural en cuanto la reflexión temática ofrece una lectura crítica para una pedagogía transformativa.

Veamos la continuación, la reflexión temática fruto de nuestra lectura critica del libro. Los temas van haciendo eco a los presupuestos teóricos de educación intercultural defendidos y enunciados anteriormente. Nuestro viaje por los temas, empezando por la dicotomía niño Vs. adulto, donde predomina la hegemonía de este último sobre el primero, y la creación de lazos o la construcción de la relación en el contacto con la diversidad, en un segundo momento, nos permite deducir que $E l$ Principito nos da la llave para abrir la puerta al encuentro intercultural. Toda la historia se construye a partir de los encuentros e interacciones entre los personajes, diálogos, más o menos cortos, pero siempre cargados de sentido. Es la reflexión sobre esos encuentros que nos ayuda a comprender mejor el ser humano en su interacción con el otro, concluyendo que tiene que existir imperativamente reciprocidad. La relación con la diversidad ocurre en la confrontación con la diferencia, étnica, social, religiosa o de cualquier otro tipo. El libro nos da un retrato de los hombres y de la relación entre ellos, en la búsqueda incesante por el sentido de la vida en sociedad. Para nuestra lectura crítica, consideramos todas las interacciones de los personajes entre ellos y con su entorno y cómo sucede la relación con la diversidad a la luz de los presupuestos teóricos de educación intercultural, eso para todos los capítulos. Cada capítulo analizado, de apariencia sencilla, es, en la verdad, de una gran riqueza informativa para quien pretende abordar la interculturalidad en su práctica pedagógica. A lo largo de los encuentros con la diversidad, las interacciones son ora positivas y conseguidas, ora frustradas por diversos motivos (hegemonía asfixiante, problemas de comunicación, etc.). Partiendo de esas interacciones conseguimos 
delinear los presupuestos teóricos de la educación intercultural y con nuestra lectura del libro, pretendemos dar a los jóvenes, por intermedio de la actuación de sus profesores el educadores, instrumentos de reflexión para transformar su relación con el otro porque el modo cómo las relaciones se verifican en el libro, podrán ser una referencia o modelo para ellos. Efectivamente, reflexionar sobre las distintas interacciones y discutir sobre ellas, podrá ser transformador y ayudar a los alumnos a detener instrumentos para transformar su mundo e incentivar al cambio por comprender lo que está mal y lo que tiene que cambiarse. El primer tema sobre él que proponemos reflexionar, y que resumiremos, es la dicotomía niño Vs. adulto que recurre continua y transversalmente la obra en un apelo nostálgico y un enaltecimiento constante a la niñez, siempre bajo la mirada cómplice del lector. El Principito representa la niñez en cuanto que los adultos aparecen representados en los habitantes de los planetas visitados. El mundo del niño es un mundo privilegiado comparado con el del adulto y esa dicotomía nos conduce a la nostalgia de la niñez y a ese propósito, Cerisier refiere que “[...]o recurso constante às recordações de infância só têm un objetivo: desvendar o mistério da nossa existência, o sentido da nossa relación con os outros e da nossa vida[...]." ${ }^{9}$ (2013:7) El niño, aunque privilegiado, vive subyugado debajo del poder del adulto que ejerce su hegemonía, denunciada tras las memorias del Aviador, al recordar que se vio obligado a desistir de su sueño de seguir con los dibujos a causa de los adultos. El Principito, asume un papel liberador en relación a la hegemonía del adulto. Pues, quisieron que el (Aviador cuando era niño) dejase de dibujar, que desistiese de ser niño y a través del Principito, consigue todo incluso seguir dibujando para él. Se hace una crítica al universo adulto y a la manera cómo los adultos pueden destruir los sueños de los niños antes de estos lleguen a ser adultos. Entre las distintas características que diferencian adultos y niños y la reflexión acerca de esa dicotomía, comprendemos e interpretamos mejor los papeles en la sociedad y las relaciones de poder entre grupo dominante y grupo minoritario. La crítica a los hombres es dura, y muestra que muchas veces, estamos sólos entre los hombres, como dice la serpiente "On est seul aussi chez les hommes, dit le serpent." ${ }^{\prime 10}$ nos muestra también, la importancia de preservar nuestra esencia a lo largo del tiempo, mantener el niño dentro de cada uno, sin perder sus características

\footnotetext{
${ }^{9}$ Trad. nuestra: " [ ... ] El recurso constante a los recuerdos de la infancia solo tienen un objetivo: desentrañar el misterio de nuestra existencia , el significado de nuestra relación con los demás y de nuestra vida [ ... ] . "

10 Trad. nuestra: "También estamos solo entre los hombres , dijo la serpiente."
} 
como la inocencia, la capacidad de interpretar más allá del invisible, entender otra cosa que no sean números, fútiles para los ojos de los niños, ya que todos los adultos fueron niños pero pocos se acuerdan. Saint-Exupéry llama nuestra atención para que no perdamos de vista el esencial, la comprensión de los demás, de nuestro entorno, la disponibilidad y la abertura sin preconcepto que caracterizan la niñez. Por otra parte, al denunciar la hegemonía del adulto sobre el niño, podemos reflexionar sobre las relaciones de hegemonía de la cultura dominante que, a veces, abraza, de forma paternal y de superioridad las minorías en vez de tratarlas de igual para igual. Por otro lado, la visión de la niñez deja trasparecer una melancolía de la infancia y de unos tempos en los que Saint-Exupéry fue feliz, pero nos permite sobre todo conocerse mejor a si mismo, como comprobaremos seguidamente, a través del personaje del Principito, que funciona para Saint-Exupéry, a través del Aviador, como un espejo de si mismo. Efectivamente, Saint-Exupéry quiso que sus lectores lo reconociesen en su libro, por los inúmeros ecos bibliográficos que lo conectan a la obra y a su historia personal, pero quiso también que nos reconociésemos a si mismos, apelando a la memoria que tenemos de nuestra niñez. Apelar a las memorias del Aviador es una necesidad de revivir el pasado. Una reconciliación con su niñez, con su pasado, por no haber seguido sus sueños, por haber abandonado y olvidado de cuando era niño porque envejeció. Y lamenta, pues esa fue una época feliz y tranquila, sin preocupaciones. La imagen del Principito funciona como un duplo reconfortante, la presencia del niño, su manera de ser dulce, su inocencia en la solitud de SaintExupéry, representado en el Aviador. Solo el (Principito) logrará libertarlo de la oscuridad del exilio y de la guerra. La muerte del Principito, o simplemente su partida, puede aún entenderse como un viaje de conocimiento, descubierta del Yo, el pasaje de un Yo a otro Yo, más adulto. El encuentro con el Principito podrá ser un encuentro con si mismo, representando por un lado Saint-Exupéry adulto y él, cuando era niño. Funciona como un paralelo o un espejo de sí, que hace con que se reconozca en el Principito. En el episodio del agua y del pozo, en el capítulo XXV, el Aviador, al comprender que el Principito procuraba agua del pozo, comprende también su niñez y recuerda "Elle était bonne pour le cour, comme un cadeau [...] lorsque j'étais petit garçon, la lumière de l'arbre de Noël, la musique de la messe de minuit, la douceur des sourires faisaient ainsi tout le rayonnement du cadeau de Noël que je 
recevais." "Tal como el Aviador (narrador) que (d)escribe para no olvidar, SaintExupéry escribió su libro para no olvidarse de su esencia, de su ingenuidad, del niño que fue. Podemos admitir también, que en el Principito, existen dos Saint-Exupéry, el Aviador, el adulto que no quiere crecer, que no quiere olvidar y ser como las personas mayores, y el otro, aquel que dibujaba serpiente boas abiertas y cerradas, el SaintExupéry niño, que ve con el corazón, que comprende el lenguaje de los niños, de la ingenuidad y la persistencia. Será un encuentro con su Yo. Una reflexión sobre si mismo, una despedida o, mejor, una reconciliación con Saint-Exupéry niño, él que desistió de sus sueños por culpa de los adultos. Así, consideramos que el Aviador, en cuanto personaje, representa Saint-Exupéry, adulto, desadaptado a este mundo al que pertenece pero con el que no se identifica, pues Saint-Exupéry repugnaba la violencia y las guerras. El elemento del desierto tampoco es mero acaso, en el Principito. De igual manera que sus memorias son esenciales para avanzar, el desierto desempeña un papel esencial, acercando a Saint-Exupéry de sus personajes. Cerisier refiere que Saint-Exupéry decía que “[...] é através da experiência do deserto, da solidão - quer sejam dunas ou nuvens, quer sejam montanhas geladas ou sozinho num arranha-céus de Nova Iorque-, que se alcança a verdadeira presença, a de nós próprios e a de nós no mundo" ${ }^{12}$ (2010:12). Esa afirmación revela la capacidad de descentrarse, de mirar para si mismo y conocerse mejor. La presencia del desierto es un encuentro de nosotros con el mundo. Drewermann (1992) refiere que en el lenguaje de SaintExupéry, desierto representa un deserto de hombres, un lugar vacío y de solitud, no apenas un punto en el espacio, sino una situación absurda, de sequedad humana, un montón de elementos frívolos e inútiles. La reflexión sobre ese tema es de gran importancia ya que la adquisición de la competencia cultural supone, también, además de aceptar y reconocer la alteridad, aprender a situarse a si mismo en relación a su propia cultura y en relación a la dinámica en la que se insiere y este es el camino que sigue Saint-Exupéry en relación a su propia cultura que ya no reconoce por un lado, por eso la necesidad de volver a las memorias y por otro, acepta y comprende que pertenece a esa cultura. No se pretende que se ponga en causa su propia cultura, los

11 Trad. nuestra: "Era bueno para el corazón , como un regalo [ ... ] cuando yo era un niño , la luz del árbol de Navidad, la música de la misa de medianoche, la ternura de las sonrisas hacían toda la radiación del regalo de Navidad que estaba recibiendo."

12 Trad. nuestra:" [ ... ] Es a través de la experiencia del desierto, de la soledad - que sean dunas o nubes , o que sean heladas montañas o que estemos solos en rascacielos de Nueva Iorque- , que logra la verdadera presencia , la de nosotros mismos y la de nosotros en el mundo." 
valores profundos de la misma, sino que se reflexione sobre una procura de identidad cultural y personal que ayudará a ser más transigente con la alteridad. Por un lado el Principito puede leerse como un recuerdo codificado de la niñez, una especie de sueño regenerador personal, como la reconciliación con el pasado, en cuanto nos muestra como podemos conocernos mejor. Por otra, indícanos cómo podemos crear lazos y construir relaciones.

Esa temática es introducida en el capítulo XXI, que constituye un episodio clave de la historia, el encuentro del Principito con el Zorro, deseoso de ser "apprivoisé" que significa cautivar o como dice el propio Zorro, es "crear lazos". En ese capítulo, se explican valores como la amistad, el amor y la confianza, entre otros. A partir de ese encuentro son revelados los enseñamientos y las instrucciones a seguir para la construcción de la relación. Todo son pistas y orientaciones que explican minuciosamente el riguroso proceso de crear lazos, con todos los rituales necesarios. Son esas pistas que iremos recurrir. En la obra aparece esta frase "Il était une fois un petit prince qui habitait une planète à peine plus grande que lui, et qui avait besoin d'un ami..." ${ }^{\prime 3}$ Así, a Saint-Exupéry, le gustaría haber empezado su historia, con una frase de una riqueza de significado indiscutible y que podría resumir la historia de $E l$ Principito. Además de huir da su rosa, el hecho de que busca a un amigo fue uno de los motivos que originó el viaje del Principito y la frase sugiere la búsqueda de interacción, de convivio y de creación de lazos. Pues amigo es aquel con quien creamos lazos, aspecto tan importante para Saint-Exupéry al punto de dedicar su libro a uno de sus amigos, Léon Werth. A ese propósito, Drewermann (19992:61) dice que " le sens des choses ne résident pas en elles-mêmes, mais dans leur "lien", et ce lien se défait s'il y a confusion des relations et des responsabilités." ${ }^{14}$ Efectivamente, una relación asienta en la complicidad y en el compartir, existe responsabilidad de ambas las partes, una reciprocidad. En la amistad tampoco existen jerarquías. Así, de acuerdo con lo que fue enunciado en la teoría, uno no puede dominar o subyugar al otro, pues la hegemonía de una de las partes es impeditiva a la concretización de la relación. Por otro lado, también no se puede querer que el otro

\footnotetext{
${ }^{13}$ Saint-Exupéry, Le Petit Prince, p.20. Trad.nuestra: “ Eráse una vez un principito que vivía en un planeta apenas más grande que él, y que necesitaba un amigo."

14 Drewermann, E., L'essentiel est invisible, p.61. Trad.nuestra: " el significado de las cosas no residen en sí mismos , sino en su " vínculo" , y este vínculo se deshace si hay confusión de relaciones y de responsabilidades."
} 
sea moldado para que sea igual a nosotros o actúe como nosotros. Debe respectarse en su integridad y en sus diferencias. Hay que salir del etnocentrismo y del egoísmo. Ser amigo es preocuparse con el otro, es serle útil. Curiosamente, es el Zorro quien da al Principito todas esas indicaciones, de manera explícita y precisa y le explica minuciosamente cómo crear lazos. La abertura y disponibilidad del Principito en interactuar con el Zorro permite que se cree un clima propicio al diálogo. Demuestra que no tiene preconceptos, ni usa estereotipos en relación al Zorro, pues apenas quiere ser su amigo. Crear lazos, es así, de acuerdo con la definición del Zorro, es ser diferente y único, dentro de las semejanzas, porque precisan uno del otro, como el Principito y su flor. Crear lazos exige reciprocidad, es ser único para alguien, transformando la diferencia en riqueza para el otro. Por otro lado, ser único también es mirar para las cosas de una manera diferente, más comprometida. El Zorro pasaría a mirar para los campos de trigo con otros ojos. Alias, este será el secreto que el Zorro irá ofrecer al Principito. Con el encuentro concertado entre ambos, Principito y Zorra, la descubierta es recíproca y ambos ganan con sus diferencias y con el hecho de ser útil al otro. El Zorro explica de qué manera se verifica esa utilidad y riqueza de la relación, refiriendo que los campos de trigo son inútiles para ella ya que no come pan, sin embargo, por acordarle el pelo del Principito, a causa de su color, esos le gustarán porque le acordarán el Principito. Indica también al Principito que la descubierta del otro debe de ser progresiva . Crear lazos exige por lo tanto dedicación y preocupación con el otro, así enseña el Zorro. Crear lazos, es crear rutinas y puntos de encuentro con el otro. Crear lazos es además hablar la misma lengua para poderse comunicar. Finalmente, cuando se crean lazos ambos enriquecen. Notemos que el campo cromático escogido no fue al acaso, los colores son un elemento importante, el color del miel, el color del oro, el color del trigo, el color de las estrellas, el color del sol. Todas evocan un mismo color, recordando el oro, tal como el pelo del Principito, como se todos os elementos evocasen esa riqueza que se gana cuando se crean lazos. Con la análisis de la forma como ocurren los encuentros con la diversidad se ponen en práctica todos los enseñamientos aprendidos anteriormente sobre la interacción y el diálogo intercultural defendidos en el primer capítulo. Referimos la importancia de crearse rutinas, o sea, puntos de encuentro, en cuanto se respecta el otro sin dejar de oírlo, mismo en los momentos de silencio, sin relación de superioridad, de igual para igual. Es importante para la interacción hablar con el otro una misma lengua para 
poder comunicarse sin preconceptos, ni ideas preconcebidas, hace falta mostrarse receptivo y disponible para conocer la diferencia y interactuar con ella. Con el Principito se aprende a construir la relación y a crear lazos sin importarse con las diferencias, por la riqueza que con ellas se gana. Sin embargo, estas etapas y condiciones descritas por el Zorro y que hacen eco a los presupuestos teóricos de la educación intercultural, se encuentren, como referimos, en todos los encuentros entre los distintos personajes y deben ser interpretados más profundamente por lo que proponemos comprender mejor cómo efectivamente se concretizan esos presupuestos enunciados por reflexión que se sigue sobre los temas implícitos en el anterior.

En la obra todo gira alrededor de lo que se ve o no se ve, notemos que estamos delante de otra dicotomía que, curiosamente o no, inicia al mismo tiempo que la dicotomía que analizamos anteriormente, del niño Vs. Adulto, a partir del capítulo I, con el dibujo de la serpiente boa abierta y de la serpiente boa cerrada. Ora se ve el interior de la serpiente boa, tragando un elefante, ora no se ve y, en ese caso, el dibujo más se parece con un sombrero. Si reflexionamos sobre esas dos imágenes, la de la serpiente boa con el elefante en su interior y la del "sombrero", observamos que quien ve correctamente el dibujo, además del Aviador (cuando era niño), es el Principito en cuanto que los adultos no entienden lo que representa. Esta observación no es un mero acaso. Pues como vimos, y si consideramos que el Principito representa el universo de los niños, ellos sólo tienen la capacidad de ver para allá de lo que ven los ojos. Esa es la cuestión aquí porque "el esencial es invisible a los ojos”. La caja con la oveja es apenas otro ejemplo de lo acabamos de argumentar. El Aviador dibujó una caja que muestra al Principito, pero ambos saben que si la miran con sus ojos atentos, lograrán ver lo que hay más allá del dibujo. Y lo que ven, es una ovejita durmiendo dentro de la caja. El verbo "ver" gana el significado de comprender, interpretar, imaginar. Por otro lado, la capacidad de ver allá de lo que ven los ojos, puede extenderse para lo que vemos cuando miramos algo o a alguien. La primera percepción que tenemos es su apariencia, que es lo que está visible, como su aspecto físico, por ejemplo. Y muchas veces, eso puede llevar a la discriminación a causa de los preconceptos. Los estereotipos y preconceptos son impeditivos a la interacción, a causa de ellos no existe disponibilidad para el otro. A ese propósito, Perotti alerta que 
impossível neutralizar este tipo de preconceptos através de uma argumentación racional. É necessário fazer apelo a situações novas e concretas para os abalar." ${ }^{15}(1994: 53)$

por su vez, Albert Einstein decía también que "É más fácil desintegrar un átomo que um preconceito"(revista Sciences et Avenir, 26/08/15) . Así, la reflexión sobre los encuentros entre los personajes se plantea como una cuestión de la máxima importancia cuando denuncian los preconceptos o los modos errados de ver y mirar al otro. Y en la obra, el preconcepto se denuncia, más explícitamente, en el capítulo IV, con la referencia al astrónomo turco que no consiguió transmitir con éxito los resultados de su descubrimiento, por haber sido inmediatamente descredibilizado por su ropa. Los preconceptos impiden que se concretice la relación. Frecuentemente, el desconocimiento provoca miedo y distancia, conocer el otro y su cultura es importante, aunque no fundamental como ya dijimos y vamos a ver la continuación. El viaje del Principito por los planetas es la descubierta de las características de sus habitantes, en la verdad, es la descubierta de la alteridad. El Principito intenta conocer mejor a sus habitantes para mejor comprender algunas actitudes que considera raras de su punto de vista. Sigue preguntando a cada uno, informaciones para conocerles mejor. Sin embargo, para el Principito, las actitudes de los habitantes le parecen inútiles y absurdas, no obstante el conocimiento que consigue, no es suficiente para establecer una relación con ellos, para interactuar. Eso comprueba lo que ya explicamos, que el conocimiento del otro no es suficiente para interactuar con él, pues desarrollar una competencia intercultural no puede basarse solo en el conocimiento de otras culturas, como defiende Perotti (1994):

On peut très bien être expert dans la connaissance intellectuelle d'une culture tout en nourrissant une antipathie plus o moins aigue pour les groupes et les individus qui en relèvent. Ce n'est pas tant ces savoirs à caractère ethnographique qui garantissent la prise en compte de la diversité culturelle mais plutôt l'acceptation et la reconnaissance de celle-ci. ${ }^{16}$

\footnotetext{
${ }^{15}$ Trad.nuestra: “[ El] problema de la Educación intercultural es que es prácticamente imposible de neutralizar esos preconceptos través de la argumentación racional. Es necesario hacer un llamamiento a situaciones nuevas y concretas para sacudirlos."

${ }^{16}$ Trad. nuestra: "Bien puede serse experto en el conocimiento intelectual de una cultura mientras que alimenta la antipatía más o menos aguda para los grupos e individuos que cubre. Esto no es tanto el conocimiento a nivel etnográfico que garantizan la inclusión de la diversidad cultural sino la aceptación y el reconocimiento de la misma."
} 
La aceptación y el reconocimiento de la diversidad son importantes para la construcción de la relación, pelo hace falta mucho más. En esos encuentros del Principito con los habitantes de los planetas visitados, no se logran interacciones, ni se crean lazos, porque esos habitantes solo piensan en si mismos, viven centrados en su propia persona, imposibilitando la interacción. El viaje interplanetario del Principito demuestra que el conocimiento no es suficiente para crear lazos. Observamos que en el contacto con los habitantes, las preguntas son dirigidas a ellos, estos nunca colocan preguntas al Principito. Y para que haya diálogo, tiene que haber reciprocidad. Probablemente, no había ganas de comunicar por parte de esos habitantes y la comunicación es fundamental para la relación intercultural.

Tras esta reflexión, fruto de nuestra lectura crítica, presentamos a continuación el diseño de un proyecto internet que utiliza El Principito como recurso didáctico para una educación intercultural. Es la parte más dinámica de la investigación, la que presenta recursos didácticos directamente implementables en el aula. Es un proyecto en construcción pero porque defendemos que la relación está en el centro de la educación intercultural y porque creemos que la reflexión conduce la transformación surge en la secuencia de toda la reflexión conducida a lo largo de la investigación como resultado de lo que estudiamos. El proyecto internet pretende un abordaje interactivo y reflexivo a la obra de El Principito por su explotación activa y orientada. Proponemos mirar hacía la obra en cuanto recurso y estrategia para trabajar la interculturalidad con base en los presupuestos defendidos en la teoría. Las actividades son presentadas a través de reflexiones sobre las temáticas ya debatidas como el encuentro con la diferencia, crear lazos, mirar para una misma realidad sobre distintos puntos de vista, etc.. En el proyecto, disponibilizamos un conjunto de orientaciones de explotación y de reflexión, para cada capítulo, organizadas en temáticas para usar el libro como instrumento didáctico. Al mismo tiempo, algunos capítulos ofrecen puntos de partida para otras actividades de intertextualidad diversificadas sobre interculturalidad. El proyecto internet se basa en el compartir y en la interacción. Proponemos en todos los capítulos, y para cada actividad, cajás de comentarios como en las redes sociales para que los intervinientes del proyecto rellenen, con el objetivo de enriquecer la experiencia de los alumnos por el cambio de ideas. Por otro lado, el espacio más interactivo, el blog y el chat, inclusos en la plataforma interactiva, funcionan como espacio de convergencia de ideas y permiten compartir productos, para que sea un instrumento para todos, al servicio del enriquecimiento que las diferencias ofrecen. Fue nuestro objetivo conducir y orientar a los profesores y educadores en una reflexión sobre las cuestiones interculturales por la explotación del 
libro en una perspectiva nueva. Las etapas que proponemos en cada capítulo siguen un modelo sencillo. Sugerimos previamente una lectura atenta del capítulo, seguida de una focalización más especifica en determinadas frases o trozos clave del capítulo. Seguidamente, el profesor/educador podrá, con recurso a las actividades propuestas, estimular la reflexión y el debate. A medida que las actividades se van desarrollando, podrán registrarse las intervenciones más pertinentes de los alumnos para posteriormente compartirlas con los otros miembros participantes del proyecto, a través de los comentarios. Por otro lado, si los alumnos demuestran creatividad para concretizar un producto final, podrán compartirlo y divulgarlo en la plataforma interactiva. El objetivo es que la plataforma interactiva funcione como punto de convergencia y de diálogo intercultural. El proyecto titulado On est tous des Petits Princes. Todos somos Principitos. Somos todos Principitos. We are all Little Princes, podrá ser accedido después de seleccionada la lengua pretendida (PT, EN, FR y ES) en la página de login a partir de http://gordynolga.wix.com/proyectolga y carece de inscripción y aceptación previa. La idea del nombre nació del hecho de tratarse de nuestro deseo que los niños/alumnos se sienten como parte de un conjunto al mismo tiempo que todos son héroes y personaje principal del libro que representa la infancia como espacio privilegiado. Siendo un proyecto que fomenta la interculturalidad, nos parece pertinente permitir el acceso al mismo en varias lenguas llegando así a un número mayor de alumnos, independientemente de su origen geográfica. Por otro lado, optamos por un proyecto online porque en la era de la informática, de las telecomunicaciones y de las facilidades en disminuir distancias gracias a internet, proponer un proyecto internet permite garantizar a todos el acceso a él, independientemente de su país de origen. Proponemos la creación de un espacio plurilingüe donde los alumnos de varias escuelas y de varios países puedan compartir sus reflexiones. Efectivamente, Perotti (1994:79) defiende que

Um projeto de educação intercultural não pode ter sucesso a não ser através de um trabalho em equipa onde os vários educadores, portadores de saberes diferentes, interagem e se enriquecem mutuamente, descobrindo a existência de diversas maneiras de ser e de viver. ${ }^{17}$

De esa afirmación, nació nuestra propuesta de proyecto que promueve el encuentro intercultural y posibilita el intercambio de ideas, de puntos comunes o de diferencias

\footnotetext{
${ }^{17}$ Trad.nuestra: "Un proyecto de educación intercultural no puede tener éxito a menos que a través de un trabajo en equipo donde varios educadores, personas con conocimientos diferentes, interactúan y se enriquecen mutuamente, descubriendo la existencia de diferentes formas de ser y de vivir."
} 
enriquecedoras de la experiencia de cada alumno. Proponemos un trabajo en conjunto, a partir de una misma obra, accesible en la(s) lengua(s) de los alumnos, que, como demostramos, aborda temas universales, accesibles y comunes a todos. La particularidad de poder recorrerse a las varias traducciones de una misma obra, ofrece la posibilidad de trabajar en conjunto a partir del acceso a un proyecto plurilingüe y facilita el contacto con sus culturas y vivencias en cuanto fomenta el compartir. La página inicial o Home page presenta todos los recursos disponibles del proyecto y es a partir de ella que se puede acceder a los mismos. Así, a partir de esa pantalla se consigue navegar por las diferentes secciones del proyecto. Existen seis secciones por las cuales se puede navegar en el proyecto, identificadas por el título que las identifica, y abriendo por una enlace destacado con letras amarillas y son las siguientes:

- el proyecto: contiene todas las indicaciones e instrucciones para utilizar el site, tal como la lista de los miembros colaboradores y los guiones para profesores y los cuestionarios a aplicar;

- las Actividades por capítulos: permiten la explotación de la obra por la reflexión con vista a una promoción del encuentro intercultural. Esta sección presenta un conjunto de recursos directamente aplicables en aula y que desarrollaremos más adelante;

- los Temas: esta sección propone la explotación de la obra a través de las temáticas que siguen los presupuestos teóricos de la educación intercultural a partir de actividades de intertextualidades;

- los contactos: en esta sección se encuentra, además de un formulario propio que permite contactar directamente con los responsables del proyecto, una dirección electrónica de contacto para quien pretenda plantear cuestiones o dar sugerencias;

- la Plataforma interactiva : esta sección representa el punto de encuentro, de partilha y pretende promover el contacto de todos los intervinientes en el proyecto. En esta sección, también existe un blog donde serán regularmente publicadas las novedades relativas al proyecto, las noticias, entre otras informaciones. Podremos encontrar ahí un chat y un fórum, donde será posible comunicar en tempo real y compartir ideas o plantear cuestiones.

Veamos, a continuación, más detalladamente cada una de las seis secciones del 
proyecto.

La subsección como funciona el site explica, paso a paso, el proyecto e indica, en detalle, como acceder a las páginas del proyecto y su utilización ; Más abajo, la subsección miembros lista los profesores/educadores invitados y que participaban inicialmente en el proyecto en varios países (Francia, Portugal, España e Inglaterra). La idea inicial se basaba en el presupuesto de que podrían trabajar en colaboración varios niveles de enseñanza, de varias asignaturas, de varias escuelas y de varios países, para que fuese un proyecto intercultural e interdisciplinar. La subsección cuestionarios presenta varios cuestionarios online disponibles para que sean aplicados antes y después de la experimentación del proyecto.

La sección Actividades por capítulos, presenta actividades de explotación y de reflexión a partir de todos los capítulos del libro. Es a través de la reflexión sobre las diferentes temáticas que proponemos abordar la educación intercultural, como ya referimos. Para esa finalidad, partiremos de la reflexión basada en la experiencia y vivencias de cada niño, para conducirlos a reflexionar sobre los temas y/o las situaciones presentadas, dándoles la capacidad de actuar en situaciones de discriminación. Pues, según Perotti (1994) es a partir del niño y de la heterogeneidad del aula (diferencias nacional, étnica, social, diferencias de lengua, de edad, de sexo) que el profesor puede preparar el joven para (con)vivir en una sociedad donde las particularidades se exprimen frecuentemente en la desigualdad y en la discriminación. Esa sección presenta la explotación, capítulo a capítulo, y abre con una pantalla que presenta los veinte y siete capítulos representados, cada uno, por un dibujo original del libro para que sea más fácil su identificación, además existirá también una sencilla descripción de cada uno. Todos los capítulos están organizados de la misma forma, pudiéndose encontrar el texto audio del capítulo, su explotación temática y actividades de intertextualidad, cuando disponible, y el respetivo guión para el profesor/educador. Después de seleccionar el capítulo, la pagina abre con un botón "pulse para oír" y permitirá oír la versión audio del capítulo elegido, que podrá eventualmente acompañarse de la versión escrita también disponible en la página inicial o Home page. Aparece la identificación del/de los tema(s) a explotar en ese capítulo, que funcionan al mismo tempo como enlaces a la sección Temas, que analizaremos posteriormente, y que permite una explotación de la obra por temas en 
alternativa a la explotación por capítulos. Debajo del título, se presenta un trozo del texto de acuerdo con su pertinencia, y el alumno es invitado a reflexionar sobre el mismo, a través de actividades de reflexión que desarrollaremos más adelante. La página ofrece también la posibilidad de navegar por los capítulos, seleccionando el pretendido, o regresar al anterior o avanzando para el capítulo siguiente. Antes de iniciar la explotación del capítulo sugerimos al profesor/educador que lea el guión propuesto o la ficha del profesor disponible para descargar en la pagina de explotación de cada capítulo, a partir de las preguntas que orientan su reflexión sobre el sentido del encuentro, de las injusticias, de algunas cuestiones planteadas en el propio trozo de texto y siempre a partir de las experiencias de los alumnos. Se invita al alumno a compartir sus ideas y puntos de vista sobre los problemas planteados a partir del trozo presentado. La caja de comentarios, igual a las que se encuentran en las redes sociales, también invitan los alumnos a compartir ideas y a comentar las de los otros alumnos. Los alumnos pueden escribir y registrar sus conclusiones, que serán leídas por otros alumnos que, por su vez, podrán comentar y opinar. Se pretende de esta forma crear una dinámica que incentive a los alumnos a comunicar entre ellos, compartiendo sus opiniones y enriqueciendo sus experiencias con las de otros alumnos, siempre tras la vigilancia del profesor/educador. De igual manera a las redes sociales, existe la posibilidad de dejar un "me gusta" en las opiniones publicadas dando más interés a su participación. Además de las actividades de reflexión, conducidas a partir de trozos seleccionados y organizados por temas en el capítulo, la página propone la explotación temática a través de la intertextualidad al seleccionar el respectivo botón.

La sección con las actividades de intertextualidad corresponde à página dos temas donde son presentadas y organizadas temáticamente. Se puede, por lo tanto acceder desde la página inicial directamente para esa sección o através de la exploración de los capítulos, acaso el profesor/educador pretenda completar la reflexión con los temas del capítulo enriqueciendo la misma con otras actividades relacionadas con la temática y que presentamos seguidamente. La sección de temas, presenta un conjunto de actividades diversificadas y organizadas a partir de temáticas que responden a los presupuestos de la educación intercultural y que, con la orientación del profesor/educador, invitan a los alumnos a explorar y profundizar algunas temáticas estudiadas en la obra. Podrán las mismas ser propuestas como introducción de un 
determinado capítulo donde el tema es estudiado, o también, como actividades complementar y como consolidación a la reflexión anteriormente conducida en los capítulos. Si el profesor/educador desea, las mismas podrán también ser propuestas independientemente de la explotación de la obra, ya que no dependen de la misma para que sean realizadas. Sin embargo, habrá siempre la indicación del lo(s) capítulo(s) dónde se puede trabajar o encontrar los temas en cuestión. La página presenta diferentes temas que, en su mayoría, corresponden a los temas que desarrollamos en nuestra investigación y que analizamos a la luz de los presupuestos teóricos de la educación intercultural. Las páginas de explotación temáticas e de intertextualidad tendrán siempre la misma presentación: el título, el ícono para volver a las actividades (por capítulos), la identificación del tema y un texto de abertura en introducción al tema. En un primer lugar, remete para el los capítulo(s) donde se podrá encontrar el tema, contextualizando el mismo, de acuerdo con una pasaje o episodio de la obra. Seguidamente, seguirán algunas consideraciones generales sobre el tema y finalmente, se propondrán actividades diversas y diversificadas, basadas en la reflexión. El concepto se mantiene el mismo que en la sección de las actividades propuestas por capítulos. El aluno es invitado a reflexionar sobre unas cuestiones que le orienta en una tarea. Como ejemplo de actividad, mostramos en el tema de los preconceptos y estereotipos, una imagen para observar. La imagen representa un médico, serio, ropa blanca y estetoscopio en los hombros. En un segundo momento, se pide al alumno para pasar con el ratón del ordenador en la imagen qua está al lado, para que descubrir la misma persona, pero de esta vez sin ropa blanca ni el estetoscopio y el cuerpo todo tatuado. Después de esa observación, un conjunto de cuestiones de reflexión son propuestas. Todas las opiniones, los comentarios y las conclusiones podrán ser registradas en el espacio de comentarios para el efecto, siendo publicadas y visibles por los otros alumnos, que por su vez, las podrán comentar también. En la misma página, se propone también un conjunto de actividades en la secuencia de la anterior y siempre con el mismo objetivo: que los alumnos reflexionen sobre las consecuencias de las ideas preconcebidas y el cuanto pueden frecuentemente ser absurdas a punto de conducir a falsos juicos de valor sobre determinadas personas. Los alumnos son otra vez invitados a debatir sobre su experiencia para enriquecer el diálogo y la reflexión. En esta sección hay también un banco de imágenes para trabajar y reflexionar la interculturalidad. 
La sección de la Plataforma interactiva es el punto de encuentro, convergencia, de compartir y de conversa de todos los miembros del proyecto. Se compone de un blog, un chat y un fórum. Es la sección del proyecto más dinámica en su utilización y es aquí que la interculturalidad se pone en práctica. En este espacio, los miembros irán divulgar, compartir y dar a conocer todos sus trabajos y sus ideas. En ella sección y en todas las otras, la participación de todos es bienvenida, profesores y educadores, pero también y principalmente los alumnos envueltos en el proyecto. Se pretende con este espacio derrubiar las barreras de la distancia, que separa cada un de los países envueltos en el proyecto, y facilitar la interacción entre todos los que participan. Uno de los objetivos asienta en la publicación regular de los trabajos realizados por los alumnos y que podrán ser vistos y comentados por todos. La idea es crear un espacio común que reúna "virtualmente" todos los participantes. Se puede acceder a la misma a partir de la pantalla inicial o Home page, directamente a través del título, o a través de la sección de presentación del proyecto, donde dice "plataforma interactiva", por

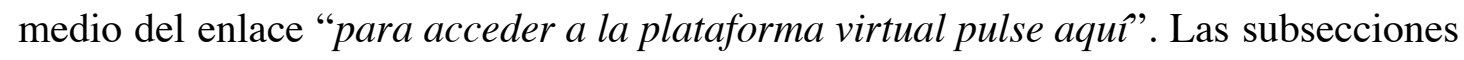
que podremos encontrar en la Plataforma virtual y que presentaremos seguidamente son el blog (página principal de la plataforma interactiva), el chat y el fórum.

La página inicial del blog presenta las informaciones actualizadas y permite que la información sea inmediatamente divulgada y compartida entre todos los intervinientes del proyecto .

El blog divulgará regularmente las informaciones importantes y las noticias relacionadas con la obra, el proyecto y cualquier otro asunto de interese común y en relación con el proyecto. Es todavía en el blog que serán propuestas actividades de grupo, particularmente creativas y que impliquen la participación de todos para un producto final común y compartido.

El blog, a la semejanza de las otras páginas de actividades, ofrece una integración con las redes sociales permitiendo que los intervinientes se inscriban a partir de un login Facebook o Google para poder comentar las informaciones, las publicaciones e interactuar con los otros intervinientes creándose así una dinámica de interacción. El blog ofrece otras dos opciones de interacción, el chat y el fórum, ubicadas en la parte lateral izquierda. 
El chat permitirá una dinámica de interactividad semejante a la que se verifica en las redes sociales, funcionando como una sala virtual, donde todos podrán comunicar en tiempo real. Será un espacio privilegiado para el intercambio lingüístico donde todos podrán participar y conocer alumnos de otras escuelas y de otros países. Los intervinientes pueden juntarse a los otros a partir de la su cuenta Facebook o Google, de acuerdo con las instrucciones que aparece en la pantalla.

El Fórum pretende ser un lugar donde se comparten dudas, ideas, y funciona de igual manera a los fórums que se pueden encontrar en internet y que juntan personas con intereses comunes, como los fórums temáticos. Para participar en el fórum los intervinientes deberán seguir los procedimientos iguales al chat, o sea, entrar con la su cuenta Facebook o Google.

Fue nuestro intuito contribuir para la construcción, a posteriori, de un proyecto centrado en una obra cuja elección se justifica tanto pelos aspectos performativos como por la temática universal y, más importante para este estudio, la construcción de las relaciones entre los personajes. El Principito es una obra adecuada, por un lado, porque no representa la cultura dominante y abre para una cultura universal. Efectivamente, la obra elegida es rica en contenidos que potencien una explotación pedagógica y puede ser estudiada sobre varios aspectos por la universalidad de los temas que propone y, por un lado, por la explotación de las inúmeras versiones que está ofrece. El Principito es un historia que demuestra cómo se consigue y se deben ultrapasar las diferencias para interactuar con el otro. Toda la obra es una historia de interacciones, de construcción de relaciones y es rica en la reflexión que permite hacerse sobre las situaciones potenciadoras de la comunicación. La perspectiva de Ouellet, en relación al acercamiento por la búsqueda de semejanzas en vez de las diferencias, ya que estas pueden levar a que se perpetúen estereotipos o que se críen nuevos, es abordada en las varias interacciones con los personajes. Los temas universales como el amor, la amistad, la tristeza, la solitud, la diferencia, permiten una explotación didáctica basada en los presupuestos de la educación intercultural ya que consolidan tópicos de reflexión sobre si mismo y el otro. Las inúmeras traducciones y adaptaciones que la obra sufrió para ser accesible en cualquier cultura o país, independientemente de su lengua y/o cultura, hacen de El Principito una obra multicultural de fácil explotación intercultural en un abordaje didáctica. La cuestión 
de la adaptación lingüística y gráfica de la obra, y de otras citadas en el presente estudio para la traducción de la obra en las más diversas lenguas y dialectos, coloca una hipótesis de reflexión interesante que podría conducir a un estudio comparativo en el sentido de entenderse cuáles los cambios lingüísticos y culturales que fueron necesarios. Por otro lado, y después de la reflexión conducida sobre los presupuestos de educación intercultural y el modo como son concretizados en la construcción de proyectos interculturales que utilizan obras de literatura infantil diversificadas, dado que abordan varias culturas en diversas lenguas, y visto que lo que se considera intercultural será el abordaje que de ellas se hace, nos lleva a cuestionar si el abordaje a la literatura infantil en proyectos interculturales tiene necesariamente que limitarse a obras cualificadas de multiculturales. O al contrario, si no será antes, el abordaje que hace el educador/ profesor que puede conducir a la reflexión y a la interculturalidad.

El Principito nos recuerda que crecemos, pero que todos fuimos un día niños. Nos muestra cómo nos debemos relacionar y nos indica pistas para el modo cómo podemos interactuar unos con los otros. Nos enseña valores como la paciencia, la conquista, la valoración de la diferencia y nosotros tenemos de interpretar el mensaje y reflexionar sobre él y sobre el poder de transformación defendido en la educación intercultural. Vemos que la diferencia enriquece y, tal como el Principito que nunca respondía a que lo que le preguntaban, también aquí la obra no nos da respuestas sino nos deja desafíos para que reflexionemos, y pistas para seguir que nos conducen al encuentro intercultural si queremos quedarnos más ricos con ese contacto con la diversidad.

Toda la obra aborda la forma de crear lazos y mirar alrededor con el corazón, de interpretar lo que nos circunda y no quedarse por las apariencias. Conocerse a si mismo, es el punto de partida por donde deberíamos comenzar. Cada capítulo es un encuentro, representa un viaje para la descubierta del otro. Cada parada representa un aprendizaje. Las viajes interplanetarias del Principito nos permiten reflexionar sobre la forma como se realizan esos encuentros y cómo se efectiva la relación y el contacto con la diversidad. Verificamos también que el contacto con la diferencia no es siempre responsable por la construcción de la relación, hace falta que existe reciprocidad y deseo de comunicar con el otro. Los viajes del Principito por los planetas no resultan siempre en interacción con sus habitantes. Importa referir que el 
hecho de querer imponer su cultura al otro, mostrando de esa manera hegemonía impide que se creen lazos. También ser egoísta o mantener un ponto de vista etnocéntrico en relación a la diferencia, o no respectar el otro en cuanto individualidad son obstáculos a la interacción con la diferencia. Por su vez, la dicotomía niño vs. adulto, es un enaltecimiento a la infancia, a los valores humanos perdidos, pues el Principito es en parte un hijo de la guerra ya que fue escrito durante la guerra. É casi una obra autobiográfica, que permite reflexionar sobre si mismo. Una reflexión que ayuda y conduce al conocimiento de si mismo defendido en la educación intercultural. Leer el Principito es casi cambiar la manera de ver el mundo, y cambiar mentalidades, pues para Valter Hugo Mãe ${ }^{18}$, “ler e reler O Principezinho $e ́$ una tarefa de felicidade. A sua candura é toda ela inteligente contra qualquer cepticismo, derrotismo, hipocrisia ou maldade. Não se trata de um libro para crianças, trata-se de um livro para todas as pessoas, inclusive crianças. $O$ Principezinho é uma reclamação de liberdade."

\footnotetext{
${ }^{18}$ Prefacio de la nueva edición de $O$ Principezinho, de Antoine de Saint-Exupéry, ed. Presença. Trad. nuestra: "Leer o releer El Principito es una tarea felicidad. Su franqueza es inteligente y totalmente en contra de cualquier escepticismo, el derrotismo, la hipocresía o el mal. Este no es un libro para niños, este es un libro para todas las personas , incluidos los niños . El Principito es una afirmación de la libertad."
} 